\title{
Possibilities for Coping Strategies Development of Management Students
}

\author{
Zuzana Birknerová1, Lucia Zbihlejová2* \\ 1 Department of Managerial Psychology, Faculty of Management, University of Prešov, Konštantínova 16, 08001 Prešov, Slovakia \\ 2 Department of Intercultural Communication, Faculty of Management, University of Prešov, Konštantínova 16, 08001 Prešov, \\ Slovakia \\ * Corresponding author, e-mail: lucia.zbihlejova@unipo.sk
}

Received: 03 June 2020, Accepted: 30 November 2020, Published online: 18 November 2021

\begin{abstract}
Coping with demanding situations is a regular part of managerial work; therefore, training in it ought also to be part of the pregraduation preparation of students of Management. From a managerial perspective, demanding situations are perceived as either unpleasant or as a potential opportunity for career advancement. This paper presents the results of an experimental research project investigating coping strategies development, specifically among students of Management. An experimental group underwent specific preparation, whereas a control group did not. The experiment was conducted on a research sample of 293 management students using the COPE (b) methodology. The experimental results confirmed statistically significant differences between the ante- and the post-measurement within the experimental group in terms of these five coping strategies: Positive reframing, Active coping, Planning, Humour, and Venting. Within the control group, no significant differences were recorded.
\end{abstract}

Keywords

coping strategies, demanding situations, management students, COPE (b) methodology

\section{Introduction}

Situations that we perceive and consider to be demanding occur naturally as part of life, and this includes a manager's working life, too. Managers are forced to handle demanding situations, regardless of whether they want it or not, in various contexts, and almost every day. Encounters with challenging situations, the way they are solved, and the residual effect of these processes can positively or negatively affect both a manager's life and the lives of their co-workers and subordinates in terms of both mental and physical health. Due to the fact that the occurrence of demanding situations cannot be significantly affected, great attention is paid by psychologists to the issues of perception, experiencing and effective resolution of these situations, rather than to the issue of preventing the occurrence of such situations. However, attention is also drawn to the states caused by these situations and their solutions. Education, teaching and training of university students of Management and other studies are a natural part of their preparation for practice.

\section{Coping with demanding situations in management}

Managers find themselves in demanding situations, irrespective of the subjective assessment of the degree of this demandingness, almost on a daily basis and in their resolution, they must often mobilise all their powers with greater or lesser success to cope with these situations, and there are also cases when they fail in to cope with them at all.

From the position of a manager who has encountered a demanding situation and has to deal with it, but also from the point of view of the organisation in which the manager operates (Horváthová et al., 2019), the decisive factor is the choice of procedure to solve the demanding situation. Research into the ways in which the manager behaves and copes with these situations receives more attention than the characteristics, specification, and taxonomy of demanding situations (Frankovský, 2001).

Not every situation is automatically perceived as demanding (Frankovský et al., 2011). The actual difficulty of the situation is perceived and interpreted by individual managers as a problem, crisis, conflict, 
complexity, inconvenience, burden, but also as a challenge (Frankovský et al., 2009). A manager's perception of a demanding situation can also be affected by the social and cultural environment in which they live (Aldwin, 2007).

The process of coping with demanding situations has been a focus of attention since the 1970s, and this area of knowledge is attracting attention even today (Amirkhan, 1990; Nurmi et al., 1996; Folkman and Moskowitz, 2004). Coping with demanding situations can be characterised either as a direct solution to a given situation by a specific intervention in its course, by planning individual activities, or by reducing tension by emotion release (easement, denial, escape, etc.) (Folkman et al., 1986). It is defined as a constantly changing cognitive and behavioural effort to handle a certain internal and/or external requirement that is assessed as a tax on, or overrun of, the manager's resources (Lazarus and Folkman, 1984).

Maddi (2013) adds that managers in demanding situations should be able to transform the stressful situation into a challenge and an advantage, analyse possible procedures, choose the best way, and then implement it. However, adequate social support and self-care, as well as the ability to maintain health and performance even in demanding situations, are essential. This requires managers to be very tough and resilient.

From the point of view of specification of the factors related to coping with demanding situations by managers, we often encounter crisis management solutions (Mellahi and Wilkinson, 2010). According to Choi et al. (2010), the difficulty and importance of managing crisis situations is confirmed by the finding that up to $90 \%$ of these crises are caused by external environmental factors, which are very difficult to control. Figueiredo et al. (2009) add that in terms of coping with demanding situations, which typically involve a high risk rate, it is necessary to focus on the difference between the possible ways of managing the risk situations and the options necessary to cope with these situations. The mismatch between these suggestions and options is another possible source of stress.

In defining the generally specified coping strategies, we also encounter the question of to what extent such strategies are an effective predictor of the behaviour of managers in a demanding situation (Frankovský et al., 2018). Reaching effective solutions to demanding situations in managerial work and the residues of these processes can substantially affect the quality of life of managers, their mental and physical health and, ultimately, the effectiveness of their management activities and the success of the organisation as a whole (Lorincová et al., 2018). They also affect other people.
In the context of these ideas, experimental research was conducted on the sample of management students.

\section{Experiment}

One of the forms of enhancing human capital in education can also be considered as the presented approach to increasing the efficiency of coping with demanding situations. The importance of managers coping with these situations effectively was the reason for focusing attention on this issue in the context of undergraduate training. In this context, we now present an experiment conducted on Management students by means of experiential learning. The experimental group consisted of Human Resource Management students who attended experiential, seminar-styled lessons themed "Coping with Demanding Situations in Human Resource Management" over the course of one academic year. The control group consisted of students with a focus on business and marketing who did not have this subject included in their study curriculum. However, both study directions (i.e. HRM plus Business and Marketing), are part of the same study programme (Management) and the core subjects of both directions are completely identical. "Coping with Demanding Situations in Human Resource Management" is an optional subject and one of the aims of this experiment is to prove that it is important enough to be included in the core subjects of both study directions.

The idea for this experiment was based on the conviction that education should aim to facilitate knowledge transfer and socialisation, as well as focus on solving demanding situations that can arise in one's management career. The acquisition of knowledge and appropriate social habits was also possible due to the inclusion of non-traditional, innovative teaching methods. Social learning has contributed to the analysis of the students' own behaviour in demanding situations, as well as the behaviour of the group as a whole (Koval'ová et al., 2019).

The programme of the seminars of "Coping with Demanding Situations in Human Resource Management" included interactive techniques, role plays, model situation solutions, as well as self-reflection through self-assessment questionnaires and feedback. One of the methods used in the experimental group was the use of simulation games (a technique that provides an artificially created environment that copies selected characteristics of real situations, allowing students to track the consequences of their decisions and respond to them).

Experiential learning has proved to be an effective approach to the experiment, since the learning process is 
managed and controlled by the students, is based on their practical experience and has a specific meaning and sense for them.

The seminar programme was divided into three basic parts. The introduction was followed by the implementation of some of the interactive techniques with subsequent analysis, discussion and final connection with the theoretical knowledge, which formed the content of the subject, as well as their use in the managerial practice.

Experiential learning, which develops creativity, elicited positive feedback from the students. The future managers were actively engaged in the individual activities and debates. The endeavour served not only to enrich their knowledge, but also to develop their managerial skills with the emphasis on coping with demanding situations. The competences acquired thereby may enable them to apply the gained knowledge in real-life managerial situations as well as in practical life.

The experimental project was conducted on the basis of comparison of the results from the experimental and the control group from the ante and the post measurement. This means that the differences between the experimental and the control group of respondents before and after the experiment were compared.

\subsection{Research sample and method}

The research sample consisted of 293 respondents, all of whom were Management students aged 18-25 ( $M=19.73$ years, $S D=1.260$ years). Of these, 110 were men $(37.5 \%)$ and 183 were women $(62.5 \%)$. The experimental group consisted of 150 students majoring in Human Resource Management (51.2\%) who participated in the seminars of the subject "Coping with Demanding Situations in Human Resource Management" during the academic year. The control group consisted of 143 Business and Marketing students (48.8\%), who did not have the subject listed in the study curriculum.

Input and output measurements were performed within the experiment. The COPE (b) questionnaire was distributed to the experimental and control groups at the beginning of the academic year (ante measurement), as well as after the application of experiential learning by means of teaching the mentioned subject to the experimental group at the end of the semester (post measurement).

\subsubsection{COPE (b) questionnaire}

The coping strategies questionnaire Brief COPE (Carver, 1997) detects how people cope with demanding and stressful situations. It consists of 28 items evaluated according to a 4-point response frequency scale of behaviour occurrence ( $1=\mathrm{I}$ haven't been doing this at all; 4 = I've been doing this a lot). The questionnaire items form 14 subscales, each represented by two items and labelled as: Religion ( $\alpha=0.82)$, Substance use $(\alpha=0.90)$, Active coping ( $\alpha=0.68)$, Planning ( $\alpha=0.73$ ), Positive reframing $(\alpha=0.64)$, Acceptance $(\alpha=0.57)$, Humour $(\alpha=0.73)$, Use of emotional support $(\alpha=0.71)$, Use of instrumental support ( $\alpha=0.64)$, Self-distraction $(\alpha=0.71)$, Denial ( $\alpha=0.54)$, Venting ( $\alpha=0.50)$, Behavioural disengagement $(\alpha=0.65)$ and Self-blame $(\alpha=0.69)$.

A higher score represents a higher degree of agreement with the use of the given coping strategy.

\subsection{Results of the experiment}

The aim of the research was experimentally to verify the effectiveness of the teaching of the subject "Coping with Demanding Situations in Human Resource Management" as well as the specific method of conducting seminars. As we have already mentioned, in the experimental group, the seminars of this subject were conducted in an experiential way. The control group did not attend the subject.

This effect was found on the basis of a comparison of the ante and the post measurement of the results of the experimental and the control group in the context of the five indicators of the COPE (b) methodology: Active Coping (focusing efforts to do something about it; taking action to improve the situation); Positive reframing (effort to see the problem in another, more positive light; finding something good in what is happening); Planning (trying to clarify your strategy, the solution procedure, what to do; a thoughtful reflection on what steps you need to take); Humour (joking about the undesired situation; making fun of this situation). In the case of the Venting strategy, the respondents scored lower in the output (talking about removing negative feelings; revealing one's negative feelings).

We therefore describe these strategies of the COPE (b) methodology for the evaluation of the experiment.

Within the experiment, the input measurements (Table 1) at the beginning of the academic year and the output measurements (Table 2) at the end after applying the experiential form of education were implemented in both the experimental and the control group.

It is clear from Table 1 that at the input (ante) measurement at the beginning of the semester, statistically significant differences were found between the experimental and control groups when assessing the five possible ways to cope with demanding situations by means of the COPE (b) methodology. The control group members were more 
Table 1 Comparison of Coping Strategies by COPE (b) in Experimental and Control Group - Input Measurement

\begin{tabular}{|c|c|c|c|c|}
\hline \multicolumn{2}{|c|}{ Coping strategies - COPE (b) } & \multirow{2}{*}{$\frac{M}{2.389}$} & \multirow{3}{*}{$\frac{t \text {-test }}{2.815}$} & \multirow{3}{*}{$\begin{array}{c}P \\
\mathbf{0 . 0 0 6}\end{array}$} \\
\hline \multirow{2}{*}{ Active coping } & Experimental group & & & \\
\hline & Control group & 2.702 & & \\
\hline \multirow{2}{*}{$\begin{array}{l}\text { Positive } \\
\text { reframing }\end{array}$} & Experimental group & 2.603 & \multirow{2}{*}{2.627} & \multirow{2}{*}{0.010} \\
\hline & Control group & 2.882 & & \\
\hline \multirow{2}{*}{ Planning } & Experimental group & 2.714 & \multirow{2}{*}{1.934} & \multirow{2}{*}{0.050} \\
\hline & Control group & 2.903 & & \\
\hline \multirow{2}{*}{ Humor } & Experimental group & 2.071 & \multirow{2}{*}{2.435} & \multirow{2}{*}{0.016} \\
\hline & Control group & 2.412 & & \\
\hline \multirow{2}{*}{ Venting } & Experimental group & 2.810 & \multirow{2}{*}{4.586} & \multirow{2}{*}{0.000} \\
\hline & Control group & 2.272 & & \\
\hline
\end{tabular}

Table 2 Comparison of Coping Strategies by COPE (b) in Experimental and Control Group - Output Measurement

\begin{tabular}{|c|c|c|c|c|}
\hline \multicolumn{2}{|c|}{ Coping strategies $-\mathrm{COPE}(\mathrm{b})$} & \multirow{2}{*}{$\frac{M}{2.807}$} & \multirow{3}{*}{$\begin{array}{l}t \text {-test } \\
2.186\end{array}$} & \multirow{3}{*}{$\begin{array}{c}p \\
\mathbf{0 . 0 3 0}\end{array}$} \\
\hline \multirow{2}{*}{ Active coping } & Experimental group & & & \\
\hline & Control group & 2.697 & & \\
\hline \multirow{2}{*}{ Positive reframing } & Experimental group & 2.984 & \multirow{2}{*}{2.362} & \multirow{2}{*}{0.020} \\
\hline & Control group & 2.771 & & \\
\hline \multirow{2}{*}{ Planning } & Experimental group & 2.960 & \multirow{2}{*}{1.952} & \multirow{2}{*}{0.050} \\
\hline & Control group & 2.850 & & \\
\hline \multirow{2}{*}{ Humor } & Experimental group & 2.630 & \multirow{2}{*}{1.609} & \multirow{2}{*}{0.110} \\
\hline & Control group & 2.375 & & \\
\hline \multirow{2}{*}{ Venting } & Experimental group & 2.105 & \multirow{2}{*}{1.446} & \multirow{2}{*}{0.151} \\
\hline & Control group & 2.260 & & \\
\hline
\end{tabular}

inclined to actively address the situation; in contrast, the members of the experimental group preferred the escape tendency. Output (Table 2) showed higher scores among those respondents who have undergone the experiential learning, the statistically significant ones being found in the COPE (b) strategies of Active coping, Positive reframing and Planning. We did not record any statistically significant differences in respect of the COPE (b) strategies of Humour and Venting.

In the experiment, the differences between the input ante measurement (beginning of the semester) and the output post measurement (end of the semester) were analysed specifically for both the experimental and the control group. We found significant differences in the experimental group (Table 3), but no significant differences in the control group (Table 4).

At the output we recorded a statistically significant difference in the five coping strategies of the COPE (b) methodology only within the experimental group.

Having completed the given subject, students of the experimental group pay more attention to actively coping with stress and a demanding situation, while they want to
Table 3 Comparison of Coping Strategies by COPE (b) and CISS in Input and Output Measurement - Experimental Group

\begin{tabular}{llccc}
\hline Coping strategies & - COPE (b) & $M$ & $t$-test & $P$ \\
\hline \multirow{2}{*}{ Active coping } & input & 2.389 & 3.780 & $\mathbf{0 . 0 0 0}$ \\
& output & $\mathbf{2 . 8 0 7}$ & & \\
\multirow{2}{*}{ Positive reframing } & input & 2.603 & & \\
& output & $\mathbf{2 . 9 8 4}$ & 3.683 & $\mathbf{0 . 0 0 0}$ \\
\multirow{4}{*}{ Planning } & input & 2.714 & & \\
& output & $\mathbf{2 . 9 6 0}$ & 2.333 & $\mathbf{0 . 0 2 1}$ \\
\multirow{2}{*}{ Humor } & input & 2.071 & & \\
& output & $\mathbf{2 . 6 2 9}$ & 4.394 & $\mathbf{0 . 0 0 0}$ \\
Venting & input & $\mathbf{2 . 8 0 9}$ & & \\
& output & 2.105 & 7.155 & $\mathbf{0 . 0 0 0}$ \\
\hline
\end{tabular}

Table 4 Comparison of Coping Strategies by COPE (b) and CISS in Input and Output Measurement - Control Group

\begin{tabular}{llccc}
\hline Coping strategies - COPE (b) & $M$ & $t$-test & $p$ \\
\hline \multirow{2}{*}{ Active coping } & input & 2.702 & & \\
& output & 2.697 & 1.250 & 0.214 \\
Positive reframing & input & 2.882 & & \\
& output & 2.771 & 1.405 & 0.163 \\
Planning & input & 2.903 & & \\
\multirow{3}{*}{ Humor } & output & 2.850 & & 0.1844 \\
& input & 2.412 & & \\
Venting & output & 2.375 & 0.217 & 0.828 \\
& input & 2.272 & & \\
\hline
\end{tabular}

take action and their efforts to make a difference. They also perceive problems more positively, and they look for something good even in a demanding situation in order to implement it in their lives. They try more to clarify what to do in an undesirable situation, looking for appropriate strategies and practices, and thinking about what steps should be taken in the given situation. They can perceive the demanding situation as less stressful, joke in the situation and make fun of it (COPE (b)).

They are less concerned about what to do next, they blame themselves less for being too emotional in the situation and getting into it, they are less angry, upset, tense and uncertain, and they do not feel nervous when they do not know how to handle the situation. Even before reacting to the problem, they thoroughly analyse it, and think about the situation in order to understand it and learn from their own mistakes; they choose a remedy procedure, sort out their priorities and devise some solutions to the problem.

Respondents in the experimental group scored significantly higher in the post measurements than in the ante measurements. There were no significant differences detected between the ante and the post measurements in 
the control group. After the experiment, a higher degree of focus was placed on an immediate solution to the demanding situation, which is a positive change in this behaviour strategy of managers.

\section{Conclusion}

The results of the experimental research project support, from both a theoretical and a methodological point of view, the multidimensional understanding of the construct of coping (Amirkhan, 1990; Frankovský and Baumgartner, 1997; Frankovský and Ištvániková, 2008; Frankovský et al., 2009) and, at the same time, they also point to the possibilities of a situational approach to exploring this issue (Carver et al., 1989; Frankovský, 2001; Holahan and Moos, 1987; Terry, 1994).

The situational concept of coping was accepted both from a methodological point of view in selecting a methodology to find out how to handle the demanding situation as well as in the implementation of the experiment itself and the content of the subject "Coping with Demanding Situations in Human Resource Management".

According to the results of the experiment, it is clear that, based on the content of the subject seminars, the changes in the coping strategies were only registered in terms of some of the factors of this process. Based on this experiment we can conclude that the use of games and role plays enables education and training to become more effective, refreshed, and more attractive. In contrast to classical methods (lecture and seminar with discussion used in the control group), the students felt relaxed and developed creativity, as well as the ability to apply new strategies of behaviour in demanding situations. Based on our findings we strongly recommend including the aforementioned subject among the core subjects for all Management study directions (Marketing, Human Resources, etc.).

\section{References}

Aldwin, C. M. (2007) "Stress, Coping, and Development: An Integrative Perspective", The Guilford Press, New York, NY, USA.

Amirkhan, J. H. (1990) "A factor analytically derived measure of coping: The Coping Strategy Indicator", Journal of Personality and Social Psychology, 59(5), pp. 1066-1074. https://doi.org/10.1037/0022-3514.59.5.1066

Birknerová, Z. (2010) "The Use of Simulation Business Games in University Education", Bulgarian Journal of Science and Education Policy (BJSEP), 4(2), pp. 202-215. [online] Available at: http://bjsep.org/getfile.php?id=77 [Accessed: 12 April 2020]

Carver, C. S. (1997) "You Want to Measure Coping But Your Protocol' Too Long: Consider the Brief COPE", International Journal of Behavioral Medicine, 4(1), pp. 92-100.

https://doi.org/10.1207/s15327558ijbm0401_6
Activities related to the solution of demanding situations are of benefit to students. They also influence the development of the decision-making and decision-taking processes, which is a natural part of the day-to-day work of managers in terms of human capital development. Role play serves to develop moral attitudes and helps to manage the burden, express personal opinions, remove prejudices, and so on. The result is an increase in healthy self-confidence, a sense of recognition, the ability to concentrate, and the management of emotional control. The extent to which managers are prepared in practice to cope with demanding situations in managerial work is an important predictor of human capital efficiency. According to Ferencová and Birknerová (2010), a game brings with it a feeling of relaxation and free decision-making, without pressure and sanctions. Knowledge and developed intuition are transformed into originality and unusualness. Birknerová (2010) states that managerial simulation games can be regarded as an appropriate tool for human capital development as well as corporate management research.

The presented findings can also be fully applied to the preparation and training of managers who are already active in practice. In this respect, experimental verification of the presented approach may represent a possible focus of further research projects, which should also take into account the limitations of the present study, such as its lack of consideration of factors such as possible gender differences, the influence of the family background or the cognitive abilities of the respondents (experiment subjects).

\section{Acknowledgement}

The contribution is one of the partial outputs of the currently-solved scientific-research project KEGA No. 012PU-4/2020.

Carver, C. S., Scheier, M. F., Weintraub, J. K. (1989) "Assessing coping strategies: A theoretically based approach", Journal of Personality and Social Psychology, 56(2), pp. 267-283. https://doi.org/10.1037/0022-3514.56.2.267

Choi, J. N., Sung, S. Y., Kim, M. U. (2010) "How Do Groups React to Unexpected Threats? Crisis Management in Organizational Teams", Social Behavior and Personality: an international journal, 38(6), pp. 805-828. https://doi.org/10.2224/sbp.2010.38.6.805

Ferencová, M., Birknerová, Z. (2010) "Experiential Learning of University Students", In: Conference Application of Management Theory in Practice IV., Bratislava, Slovakia, Paper number: 6. 
Figueiredo, E., Valente, S., Coelho, C., Pinho, L. (2009) "Coping with risk: analysis on the importance of integrating social perceptions on flood risk into management mechanisms - the case of the municipality of Águeda, Portugal", Journal of Risk Research, 12(5), pp. 581-602. https://doi.org/10.1080/13669870802511155

Folkman, S., Lazarus, R. S., Dunkel-Schetter, C., Delongis, A., Gruen, R. J. (1986) "Dynamics of a stressful encounter: Cognitive appraisal, coping, and encounter outcomes", Journal of Personality and Social Psychology, 50(5), pp. 992-1003. https://doi.org/10.1037/0022-3514.50.5.992

Folkman, S., Moskowitz, J. T. (2004) "Coping: Pitfalls and Promise", Annual Review of Psychology, 55(1), pp. 745-774. https://doi.org/10.1146/annurev.psych.55.090902.141456

Frankovský, M., Lajčin, D., Birknerová, Z. (2011) "Coping with demanding managerial work situations in the context of personality characteristics of managers", Tudományos mozaik, 8, pp. 231-238.

Frankovský, M. (2001) "Strategies of behavior in demanding situations and the situational context", Studia Psychologica, 43(4), pp. 339-344.

Frankovský, M., Baumgartner, F. (1997) "Behavior strategies in demanding life situations", Studia Psychologica, 39(2), pp. 103-109.

Frankovský, M., Birknerová, Z., Zbihlejová, L. (2018) "Specification of Changes in Coping with Demanding Situations Strategies in the Context of Management Study", International Journal of Business and Management, 2(6), pp. 11-16. https://doi.org/10.26666/rmp.ijbm.2018.6.2

Frankovský, M., Ištvániková, L. (2008) "Management of the Strategies of Behavior in the Demanding Work Situations", In: Štefko, R., Frankovský, M. (eds.) Management 2008: In Times of Global Change and Uncertainty (Part II.), University of Prešov, Prešov, Slovakia, pp. 377-388.

Frankovský, M., Ištvániková, L., Štefko, R. (2009) "Strategies of behavior in demanding managerial work situations in social contexts", Studia psychologica, 51(2-3), pp. 231-236.

Holahan, C. J., Moos, R. H. (1987) "Personal and contextual determinants of coping strategies", Journal of Personality and Social Psychology, 52(5), pp. 946-955.

https://doi.org/10.1037/0022-3514.52.5.946
Horváthová, P., Mikušová, M., Kashi, K. (2019) "Evaluation of the employees' engagement factors importance methodology including generation Y", Economic Research-Ekonomska Istraživanja, 32(1), pp. 3895-3917. https://doi.org/10.1080/1331677X.2019.1679214

Koval’ová, J., Ondrijová, I., Ratnayake Kaščáková, D. (2019) "The customers' perception of the sellers in the context of gender differences", Balkans Journal of Emerging Trends in Social Sciences, 2(1), pp. 80-87. https://doi.org/10.31410/Balkans.JETSS.2019.2.1.80-87

Lazarus, R. S., Folkman, S. (1984) "Stress, Appraisal, and Coping", Springer Publishing Company, New York, NY, USA.

Lorincová, T., Tomková, A., Suhányi, L. (2018) "Prediction of Selected Personality Characteristics of Businessmen in the Context of their Potential to Work with Customer", International Journal of Organizational Leadership, 7(1), pp. 99-105. https://doi.org/10.33844/ijol.2018.60232

Maddi, S. R. (2013) "Hardiness: Turning Stressful Circumstances into Resilient Growth", Springer, Dordrecht, Netherlands. https://doi.org/10.1007/978-94-007-5222-1

Mellahi, K., Wilkinson, A. (2010) "Managing and Coping with Organizational Failure: Introduction to the Special Issue", Group \& Organization Management, 35(5), pp. 531-541. https://doi.org/10.1177/1059601110383404

Nurmi, J.-E., Toivonen, S., Salmela-Aro, K., Eronen, S. (1996) "Optimistic, Approach-oriented, and Avoidance Strategies in Social Situations: Three Studies on Loneliness and Peer Relationships", European Journal of Personality, 10(3), pp. 201-219. https://doi.org/10.1002/(SICI)1099-0984(199609)10:3<201::AIDPER257>3.0.CO;2-\#

Terry, D. J. (1994) "Determinants of coping: The role of stable and situational factors", Journal of Personality and Social Psychology, 66(5), pp. 895-910. https://doi.org/10.1037/0022-3514.66.5.895 